Buletin JSJ, 2 (2), 2020, 101-112

Available online di: http://ejournal-balitbang.kkp.go.id/index.php/JSJ/index

\title{
PENENTUAN UMUR SIMPAN OTAK-OTAK IKAN UMKM BUNGA MAWAR DENGAN METODE EXTENDED STORAGE STUDIES (ESS)
}

\section{STORAGE LIFE DETERMINATION OF FISH CAKE PRODUCT FROM UMKM BUNGA MAWAR USING EXTENDED STORAGE STUDIES (ESS) METHOD}

\author{
Asriani ${ }^{*}$, Niken Dharmayanti, Henny Budi Purnamasari, Yudi Prasetyo Handoko, Nofi Sulistiyo \\ Rini, dan Ilyas Maulana Abdulloh \\ Politeknik Ahli Usaha Perikanan \\ JI. AUP Pasar Minggu, Jakarta Selatan \\ Email: asria6191@gmail.com
}

\begin{abstract}
ABSTRAK
Otak-otak ikan merupakan salah satu produk diversifikasi hasil perikanan yang sudah lama dikenal dan disukai oleh masyarakat di Indonesia. Otak-otak ikan yang bersifat semi basah biasanya memiliki umur simpan yang singkat sehingga penentuan informasi umur simpan produk menjadi penting. Tujuan penelitian ini adalah untuk mengetahui umur simpan dari otak-otak ikan yang diproduksi UMKM Bunga Mawar Mutu otak-otak ikan UMKM Bunga Mawar sesuai dengan SNI (7757:2013) dan usia simpan dengan metode Extended Storage Studies (ESS) . Nilai sensori produk otak-otak ikan adalah 9 Kadar air 50,19\%. Umur simpan otak-otak ikan UMKM Bunga Mawar yang dibungkus menggunakan plastik $\mathrm{PE}$ tanpa divakum pada suhu $5^{\circ} \mathrm{C}$ adalah 6 hari dan pada suhu $30^{\circ} \mathrm{C}$ adalah 3 hari.
\end{abstract}

Kata Kunci: Extended Storage Studies (ESS), otak-otak ikan, penentuan umur simpan

\begin{abstract}
Fish cake is one of the diversified fisheries products that has long been known and favored by the people in Indonesia. Semi-wet fish cake is usually having a short shelf life, that is why determining its shelf-life information becomes important. The purpose of this research was to determine the quality characteristics of raw materials and final products, nutritional value content, and shelf life of the fish cake produced by UMKM Bunga Mawar using Extended Storage Studies (ESS) method. The quality of the fish cake produced by UMKM Bunga Mawar is in accordance with SNI (7757:2013). Sensory test of fish cake was valued 9. Chemical test values of water content, were 50.19 respectively. The shelf life of the fish cake from UMKM Bunga Mawar wrapped in PE plastic without vacuuming at a temperature of $5^{\circ} \mathrm{C}$ is 6 days and at a temperature of $30^{\circ} \mathrm{C}$ is 3 days.
\end{abstract}

Keywords: Extended Storage Studies (ESS), fish cake, storage life determination

\section{PENDAHULUAN}

Otak-otak ikan merupakan salah satu produk diversifikasi hasil perikanan yang sudah lama dikenal dan disukai oleh masyarakat karena mudah disajikan dan memliki cita rasa yang khas dan dikemas menggunakan daun pisang. Otak-otak adalah modifikasi produk olahan antara bakso dan kamaboko. Fungsi teknologi pembuatan otak-otak ikan adalah sebagai upaya diversifikasi produk olahan ikan berbentuk gel yang diharapkan memiliki nilai tambah. Otakotak ikan merupakan produk gel dari daging ikan yang dicampur dengan tapioka dan bumbubumbu seperti garam, gula, santan kental, bawang putih, bawang merah, dan lada (Putra et al., 2015).

Otak-otak ikan merupakan produk basah yang memiliki umur simpan yang singkat. Salah satu faktor yang mempengaruhi kualitas daya simpan otak-otak ikan adalah cara pengemasan dan suhu penyimpanan produk tersebut. Menurut Alifah (2016), produk pangan seperti otak-otak ikan yang bersifat semi basah biasanya memiliki umur simpan yang singkat, hal ini dapat disebabkan oleh cara pengemasan yang masih sederhana seperti menggunakan daun pisang. 
Available online di: http://ejournal-balitbang.kkp.go.id/index.php/JSJ/index

Sedangkan menurut Padli (2015), umur simpan otak-otak ikan yang disimpan dalam suhu ruang akan relatif lebih singkat, yaitu 2 (dua) hari.

UMKM Bunga Mawar merupakan salah satu produsen pembuat produk olahan otak-otak ikan yang ada di Kecamatan Kronjo, Kabupaten Tangerang hasil binaan Dinas Perikanan Kabupaten Tangerang yang daya simpan produknya masih menggunakan perkiraan dan diperkirakan umur simpannya kira-kira 6 bulan. Sejauh ini, penentuan umur simpan pada otakotak ikan yang dilakukan oleh UKM yaitu menggunakan metode penyimpanan konvensional dengan membiarkan produk hingga mengalami kerusakan sampai pada waktu tertentu tanpa dilakukannya pengukuran terhadap parameter-parameter perubahan otak- otak ikan, hal Ini merupakan permasalahan yang serius mengingat umur simpan produk olahan menyangkut keamanan suatu produk. Menurut UU RI No.18 Tahun 2012 tentang pangan, setiap industri pangan wajib mencantumkan tanggal kadaluwarsa (umur simpan) pada setiap produk pangan.

Informasi mengenai umur simpan atau masa kadaluarsa suatu produk sangat diperlukan agar dapat menjangkau pasar yang lebih luas dan daya awet produk yang tinggi. Produk olahan semakin lama akan mengalami kemunduran mutu. Otak-otak ikan merupakan produk semi basah dan mengandung bahan yang dapat menyebabkan ketengikan dan tidak layak konsumsi, sehingga perlu adanya studi mengenai jenis kemasan yang cocok untuk produk otak-otak ikan serta mengetahui lama umur simpan dari produk. Oleh karena itu diperlukan analisa kembali mengenai umur simpan yang lebih akurat dengan menggunakan metode penentuan umur simpan yang sama yaitu metode Extended Storage Studies (ESS) dengan menggunakan kemasan plastik PE (polyethylene) terhadap otak-otak ikan hasil olahan UMKM Bunga Mawar.

\section{TUJUAN}

Mengetahui umur simpan produk otak-otak ikan.

\section{BAHAN DAN METODE}

\section{Bahan, Alat, dan Tempat}

Penelitian ini dilaksanakan pada tanggal 8 Maret 2020 sampai dengan 6 Juni 2020 dengan pengambilan sampel di 2 UMKM yang berada di Kecamatan Kronjo, Kabupaten Tangerang. Pengujian mutu Mikrobiologi dilakukan di Lab. Pusat Produksi Inspeksi dan Sertifikasi Hasil Perikanan (PPISHP), Jakarta Utara dan pengujian umur simpan bertempat di Laboratorium Kimia dan Laboratorium Mikrobiologi Politeknik Ahli Usaha Perikanan.

Alat yang digunakan adalah alat tulis, nampan, scoresheet, kertas saring, timbangan, , tabung reaksi, pipet, dan gelas ukur., cawan porselin, alat penjepit/tang, desikator, sendok, timbangan analitik, oven.

Bahan yang digunakan adalah; (1) Bahan baku otak-otak ikan kurisi dari UMKM Bunga Mawar yang diproduksi pada 22 Maret 2020 dengan bahan pengemas plastik polyethylene; (2) Bahan analisa kimia yang digunakan aquades, $\mathrm{HCl}$, kunyit, asam kromatofit, $\mathrm{H}_{3} \mathrm{BO}_{3}$ ind Metil Red (MM) ind Blue Cresol Green (BCG), Larutan boraks $0,1 \mathrm{~N}$, hexane.

\section{Tahapan Penelitian}

Tahapan penelitian pada Gambar 1, dilakukan penelitian pendahuluan yang bertujuan untuk mengetahui produk otak-otak ikan yang berada di Kronjo tidak mengandung bahan yang berbahaya dengan melakukan pengujian Boraks dan Formalin di 2 UMKM yang berbeda. Pengambilan sampel otak-otak ikan di UMKM terpilih di daerah Tangerang. Sampel otak-otak ikan terpilih merupakan produk yang baru diproduksi dan belum mengalami penyimpanan dikemas ulang mengunakan plastik PE sesuai dengan jumlah yang dibutuhkan yaitu 12 pcs per bungkus untuk satu hari pengujian pada tiap suhu penyimpanan. Suhu penyimpanan 
Buletin JSJ, 2 (2), 2020, 101-112

Available online di: http://ejournal-balitbang.kkp.go.id/index.php/JSJ/index

adalah suhu dingin $\left(5^{\circ} \mathrm{C}\right)$ dan suhu ruang $\left(30^{\circ} \mathrm{C}\right)$ dimulai hari ke-0 sampai hari ke-7 dan diuji dengan pengujian parameter umur simpan (kadar air dan Sensori) setiap hari.

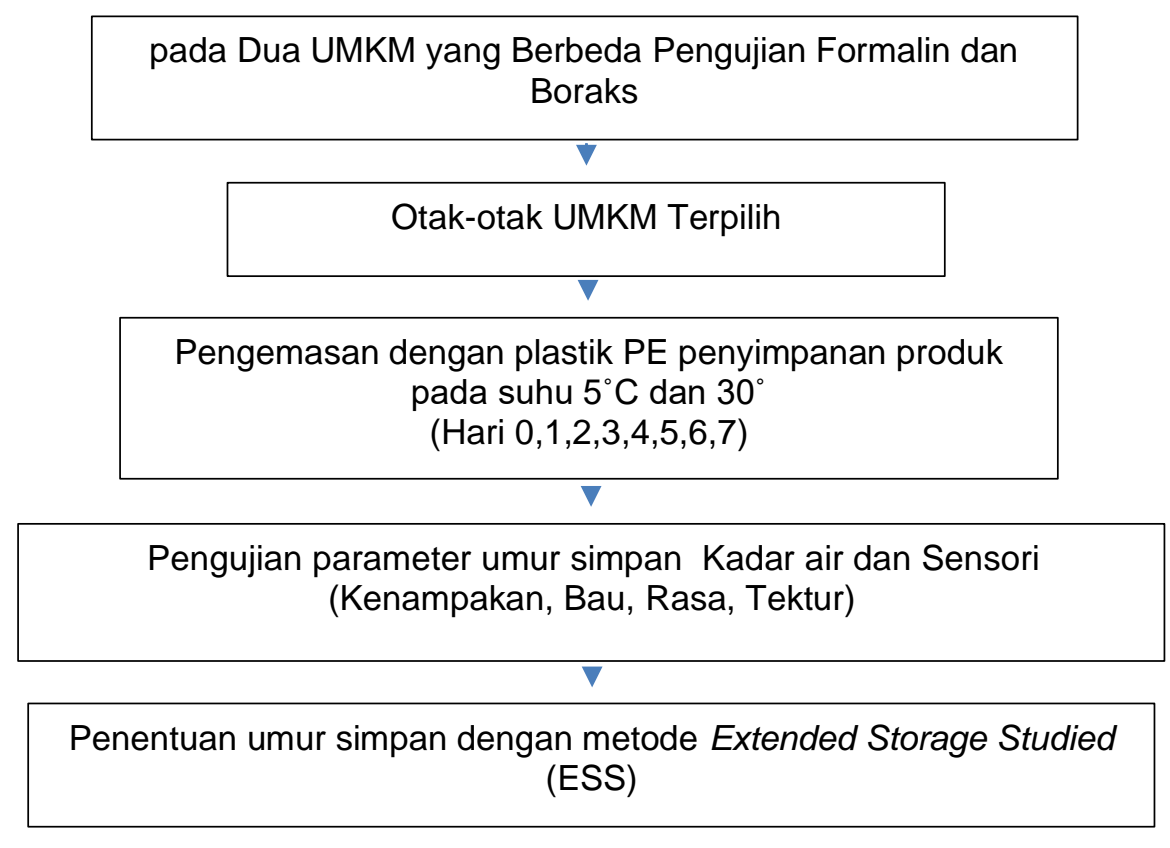

Gambar 1. Diagram Alir Tahapan Penelitian

\section{Pengujian Kadar Formaldehid/formalin (Test kit)}

Pengujian formaldehid dilakukan dengan cara kualitatif yaitu dengan menggunakan test kit merek Easy Teach. Pada tahap ekstraksi sample ditimbang $10 \mathrm{~g} \pm 0,1 \mathrm{~g}$ menggunakan erlenmeyer kemudian tambahkan $20 \mathrm{ml}$ air suling (aquadest) yang telah dipanaskan terlebih dahulu homogenkan contoh dengan homogenizer selama 1 menit kemudian sample disaring menggunakan kertas saring. Pipet $5 \mathrm{ml}$ ekstrak larutan sampel kemudian masukan kedalam tabung reaksi. Tambahkan 4 tetes reagen $A$ dan 4 tetes reagen $B$, biarkan selama 10-20 menit. Hasil pengujian positif ditandai dengan perubahan warna larutan ekstrak menjadi merah muda atau ungu.

\section{Pengujian Boraks}

Pembuatan Alat Pendeteksi Boraks Menggunakan Kertas Turmerik (Hartati, 2017) sebagai berikut: kunyit dikupas kemudaian dicuci dan diparut, air kunyit yang didapatkan lalu ditampung dan diukur menggunakan gelas ukur. Alcohol 70\% ditambahkan sebanyak 10\% dari total volume air kunyit yang didapatkan. kertas saring disiapkan, digunting persegi dengan ukuran 8 x 8cm dan dicelupkan kedalam air kunyit, dibolak balik menggunakan pinset sampai merata pada seluruh permukaan kertas saring. Kertas ini lalu diletakkan pada Loyang dan diangin-anginkan agar kering.

Analisis boraks secara kualitatif dengan kertas Turmerik (Hartati, 2017) sebagai berikut:

Sampel sebanyak $1 \mathrm{~g}$ ditimbang lalu ditambahkan akuades sebanyak $1: 10$. campuran ini lalu diblender sampai halus dan disaring menggunakan kertas saring. Cairan yang didapatkan ditempatkan dalam gelas piala. Celupkan kertas Turmerik selama 1-2 menit ke dalam cairan sampel, bila kertas turmerik berubah warna menjadi merah kecoklatan maka sampel positif mengandung boraks.

\section{Pengujian kadar air}

Pengujian dilakukan dengan cara: mengkondisikan oven pada suhu yang akan digunakan 
Available online di: http://ejournal-balitbang.kkp.go.id/index.php/JSJ/index

hingga mencapai suhu stabil. Cawan kosong dimasukan kedalam oven minimal 2 jam. Cawan kosong dipindahkan ke dalam desikator sekitar 30 menit sampai mencapai suhu ruang dan timbang bobot kosong (A). Contoh yang telah dihaluskan ditimangan sebanyak $\pm 2 \mathrm{~g}$ ke dalam cawan (B). Cawan yang telah diisi dengan contoh dimasukan ke dalam oven pada suhu $105^{\circ} \mathrm{C}$ selama $16-24$ jam. Pindahkan cawan dengan menggunakan alat penjepit ke dalam desikator selama \pm 30 menit kemudian timbang $(\mathrm{C})$. Lakukan pengujian minimal duplo( dua kali )

\section{Pengujian Sensori}

Pengujian sensori dilaksanakan dengan menggunakan score sheet otak-otak ikan sesuai SNI 7757:2013. Pengujian organoleptik tersebut hasilnya dicari dengan menggunakan perhitungan dengan rumus sebagai berikut dengan taraf kepercayaan $95 \%$ :

$$
\begin{aligned}
& \overline{\mathrm{X}}=\frac{\sum_{i=1}^{n}\left(x_{i}\right)}{n} \\
& S^{2}=\frac{\sum_{1=1}^{n}(\mathrm{xi}-\overline{\mathrm{x}})}{n} \\
& \mathrm{P}-\{\overline{\mathrm{x}}-\quad(1,96.5 / \sqrt{n})) \leq \mu \leq(\mathrm{x}+(1,96,5 / \sqrt{n})\}
\end{aligned}
$$

\section{Penentuan umur simpan}

Penentuan umur simpan dilakukan dengan metode Extended Storage Studies (ESS) dengan parameter kerusakan yang diamati adalah sensori (Kenampakan, Bau, Rasa dan Tekstur) sesuai dengan SNI 7757:2013 dan Kadar Air sesuai dengan dengan SNI 01-2354.2:2006. Pendugaan umur simpan dengan metode Extended Storage Studies (ESS), yaitu dengan membiarkan produk hingga mengalami kerusakan sampai pada waktu tertentukan kemudian dilakukannya pengukuran terhadap parameter-parameter perubahan mutu. Suhu penyimpanan yang digunakan yaitu suhu kamar $\left(30^{\circ} \mathrm{C}\right)$ dan suhu chilling $\left(5^{\circ} \mathrm{C}\right)$ dengan jenis pengemas polyethylene.

Menurut Syarief et al. (1989), pengamatan dilakukan terhadap parameter titik kritis dan atau kadar air. Penentuan umur simpan produk dengan metode konvensional dapat dilakukan dengan menganalisis kadar air suatu bahan, memplot kadar air tersebut pada grafik kemudiamenarik titik tersebut sesuai dengan kadar air kritis produk. Perpotongan antara garis hasil pengukuran kadar air dan kadar air kritis ditarik garis ke bawah sehingga dapat diketahui nilai umur simpan produk. Selain berdasarkan hasil analisis kadar air, kadar air kritis dapat ditentukan berdasarkan mutu fisik produk (sensori). Penentuan umur simpan produk pangan dapat dilihat pada Gambar 2.

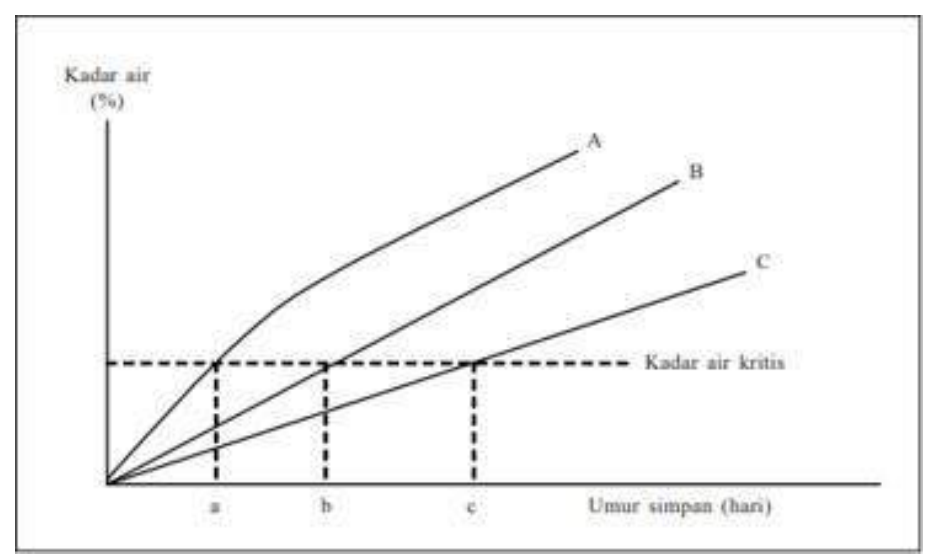

Gambar 2. Penentuan umur simpan produk pangan berdasarkan kadar air dan kadar air kritis (Syarief et al. 1989) 
Buletin JSJ, 2 (2), 2020, 101-112

Available online di: http://ejournal-balitbang.kkp.go.id/index.php/JSJ/index

\section{HASIL DAN PEMBAHASAN}

\section{Hasil Pengujian Formalin dan Boraks}

Sebelum dilakukan pengujian umur simpan terhadap otak-otak ikan, dilakukan penelitian pendahuluan untuk mengetahui produk otak-otak ikan yang berada di Kecamatan Kronjo apakah aman untuk di konsumsi dari bahan berbahaya seperti formalin dan boraks. Penentuan umur simpan juga harus dilakukan pada produk olahan yang tidak mengandung bahan tambahan berbahaya yang dapat mempertahankan mutu produk sehingga umur simpan yang didapatkan adalah umur simpan yang sebenarnya dari produk tersebut. Kabupaten Tangerang memiliki 2 (dua) UPI yang mengolah otak-otak ikan yaitu UMKM Bunga Mawar dan UMKM Amafood. Penentuan produk penting dilakukan dengan melakukan penilaian kelayakan dasar pada tiap UMKM dan pengujian bahan tambahan berbahaya formalin dan boraks karena menurut Peraturan BPOM No 7 tahun 2018 adalah pangan olahan yang baik adalah pangan yang tidak mengandung formalin dan boraks.

Penentuan produk otak-otak ikan yang akan diuji umur simpannya dilakukan dengan pengujian formalin dengan metode kualitatif, pengujian boraks dengan metode kualitatif dan berdasarkan penilaian SKP UPI skala mikro kecil. Pengujian formalin dan Boraks dilakukan pada empat sampel otak-otak ikan yang dihasilkan dari dua UMKM yang ada di Kecamatan Kronjo Kabupaten Tangerang. Pengujian formalin dan pengujian boraks dengan metode kualitatif menggunakan kertas curcumin. Hasil pengujian formalin dan Boraks dari ke empat sampel otak-otak dapat dilihat pada Tabel 1dan Tabel 2.

Tabel 1. Hasil Pengujian Formalin

\begin{tabular}{clc}
\hline Kode Sampel & \multicolumn{1}{c}{ Merk Produk } & Hasil \\
\hline A1 & Otak-otak ikan Bunga Mawar & Negatif \\
B1 & Otak-otak ikan Amafood Super & Negatif \\
B2 & Otak-otak ikan Amafood Putra & Negatif \\
B3 & Otak-otak ikan Amafood Super (Bos) & Negatif \\
\hline
\end{tabular}

Tabel 2. Hasil Pengujian Boraks

\begin{tabular}{clc}
\hline Kode Sampel & \multicolumn{1}{c}{ Merk Produk } & Hasil \\
\hline A1 & Otak-otak ikan Bunga Mawar & Negatif \\
B1 & Otak-otak ikan Amafood Super & Negatif \\
B2 & Otak-otak ikan Amafood Putra & Negatif \\
B3 & Otak-otak ikan Amafood Super (Bos) & Negatif \\
\hline
\end{tabular}

Berdasarkan Tabel 2 dan 3, Hasil pengujian formalin dan boraks pada keempat produk otakotak ikan yang diproduksi oleh dua UMKM di Krojo, Kabupaten Tangerang adalah semuanya negatif tidak mengandung bahan tambahan berbahaya formalin sehingga aman jika dikonsumsi. Pengujian ini dilakukan karena menurut Peraturan Menteri Kesehatan RI No 33 tahun 2012 tentang bahan tambahan pangan, boraks merupakan salah satu dari jenis bahan tambahan pangan yang dilarang digunakan dalam produk makanan karena dapat membahayakan Kesehatan jika dikonsumsi dan dapat mempertahankan umursimpan produk menjadi lebih lama.

\section{Pengolahan Otak-otak Ikan}

Penanganan dan pengolahan Otak-otak ikan di UMKM Bunga Mawar memiliki tahapan proses sesuai dengan SNI (7757:2013). Tahapan pembuatan otak-otak ikan yang dilakukan di UMKM Bunga Mawar terdiri dari dua tahapan yaitu pembuatan lumatan daging ikan (surimi) dan pembuatan otak-otak ikan. 
Tahapan pembuatan lumatan daging ikan (surimi) yaitu diawali dengan pembelian bahan baku ikan berasal dari tempat pelelangan ikan yang ada di Kecamatan Kronjo, Bahan baku yang digunakan ikan kurisi segar, kemudian dilakukan penimbangan menggunakan timbangan gantung, melakukan penyiangan (pembuangan kepala, isi perut dan insang), Pencucian, Penggilingan daging ikan. Pada tahapan ini biasanya surimi tidak langsung diproses menjadi otak-otak ikan, tetapi dibekukan dan disimpan dahulu di freezer karena pembelihan bahan baku tidak dilakukan setiap hari dan proses pembuatan otak- otak ikan disesuaikan dengan produksi harian. Proses pembuatan surimi ikan kurisi dapat dilihat pada Gambar 3.

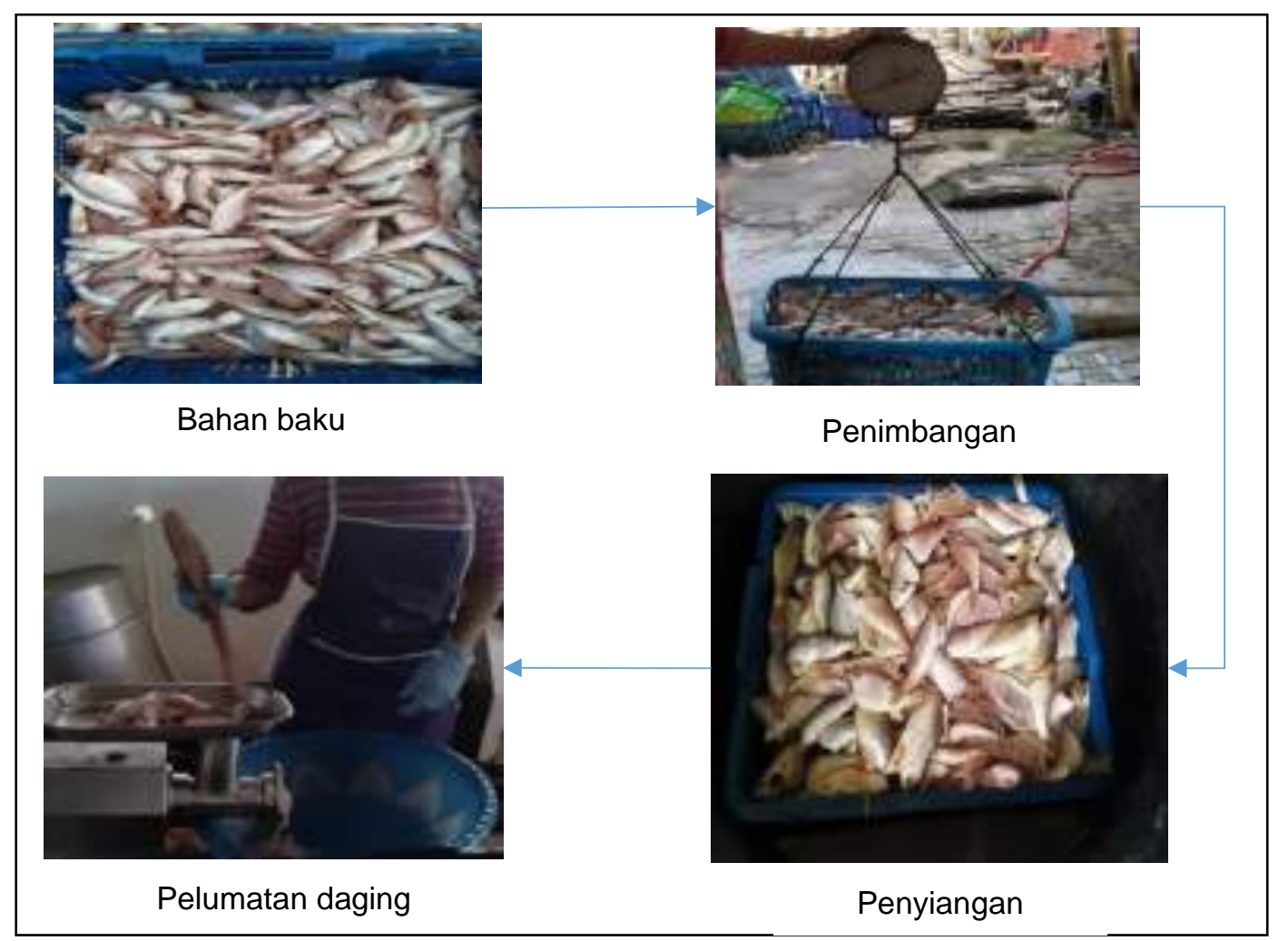

Gambar 3. Proses Pembuatan Surimi Ikan Kurisi

Pada tahapan kedua yaitu pembuatan otak-otak ikan yaitu dengan thawing surimi ikan kurisi, kemudian pencampuran dengan bahan tambahan dan bahan pembantu (lumatan daging ikan kurisi $10 \mathrm{~kg}$, tepung tapioka $10 \mathrm{~kg}$ serta tambahan bumbu rahasia dan bahan pembantu seperti air 2,5 liter dan es secukupnya) yang dicampur hingga merata dan terbentuk adonan gel strength yang kuat. Menurut Rahussidi et al., (2016) Penambahan tepung tapioka memberikan pengaruh nyata terhadap kenampakan, tekstur, gel strength, kadar air, kadar protein dan uji lipat. Kemudian dilakukan pencetakan menggunakan tangan berbentuk bulat memanjang dan perebusan dengan suhu $90-100^{\circ} \mathrm{C}$ selama 15 menit. Menurut Putra et al., (2015), suhu yang digunakan dalam perebusan otak- otak ikan antara lain $60-90^{\circ} \mathrm{C}$, dengan lama proses perebusan otak-otak antara 10 - 15 menit.

Setelah itu dilakukan pendinginan menggunakan kipas angin sampai suhu produk menjadi 25$30^{\circ} \mathrm{C}$ agar tidak terjadi over cooking, selanjutnya adalah penimbangan dengan berat 200 $\mathrm{g} /$ kemasan dan pengemasan menggunakan plastik PE kemudian ditutup menggunakan alat sealer. Pengemasan harus sesuai dengan persyaratan pengemasan bahan pangan, di mana bahan pengemas bersifat dapat melindungi kemungkinan kontaminasi mikroba, menjaga kandungan air dan lemak tidak berubah, tidak menyerap air dari luar (Winarno, 2011). 
Tahapan terakhir adalah proses pembekuan yang dilakukan di dalam freezer khusus selama semalaman, semenjak proses pengemasan primer selesai dilakukan hingga pembongkaran dilakukan pada pagi hari esoknya untuk dipindahkan ke dalam freezer penyimpanan produk akhir dengan mengatur suhu freezer $\pm-20^{\circ} \mathrm{C}$. Proses penyimpanan di freezer menggunakan sistem FIFO agar proses supply chain berjalan dengan lancar. Freezer yang digunakan berukuran 200 Liter (satu pintu). Suhu produk pada penyimpan adalah $-14{ }^{\circ} \mathrm{C}$ sampai dengan $-18^{\circ} \mathrm{C}$. Proses pembuatan otak-otak ikan dapat dilihat pada Gambar 4.

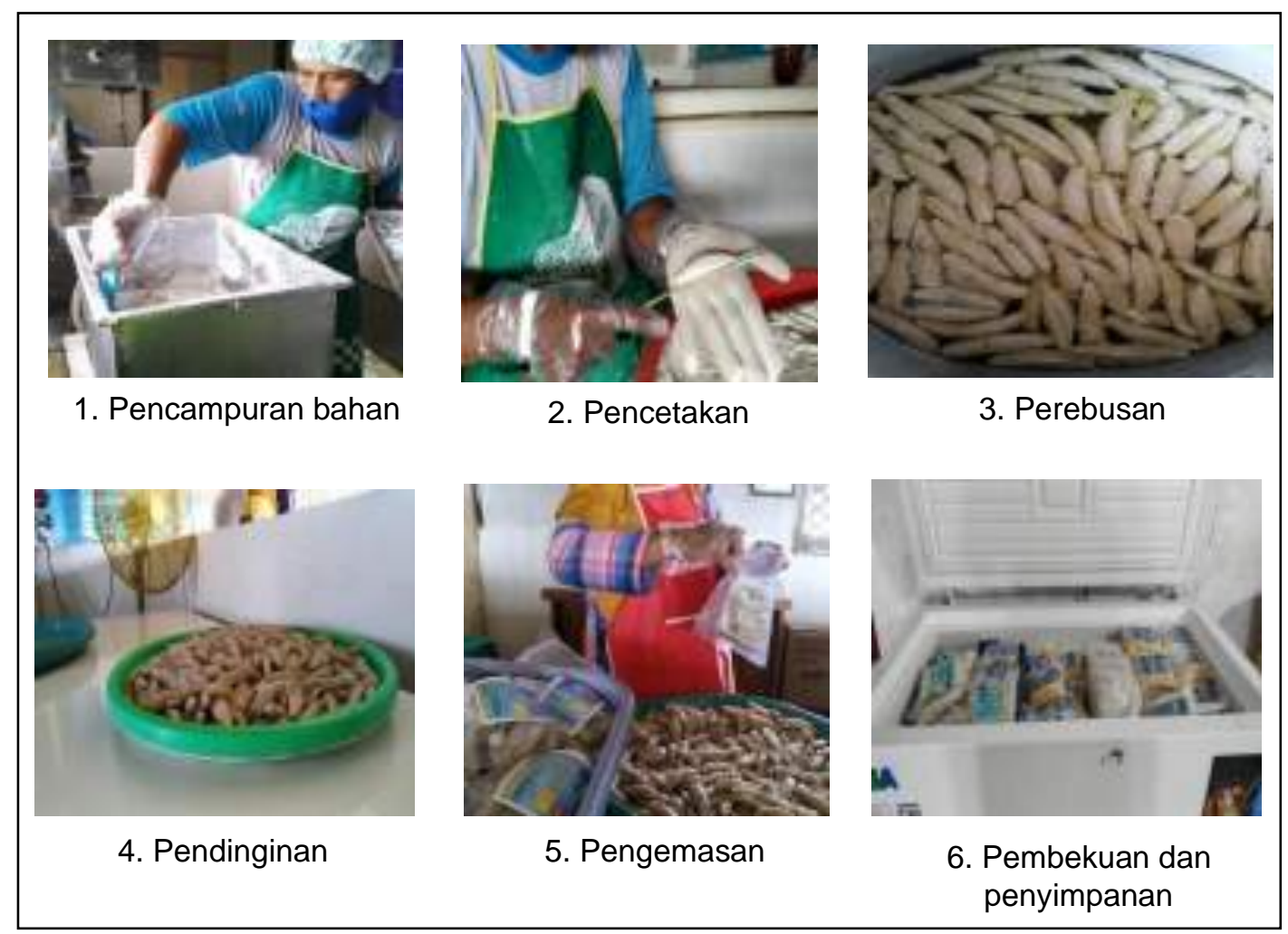

Gambar 4. Proses Pembuatan Otak-otak Ikan

\section{Pendugaan Umur Simpan Produk}

Pendugaan umur simpan produk dilakukan dengan melihat dari kinetika reaksi dasar seperti pengujian kadar air dan sensori yang kemudian ditentukan regresi linear dari setiap parameter.

\section{Kinetika Reaksi Dasar untuk Pendugaan Umur Simpan}

Kinetika reaksi meliputi laju dan mekanisme suatu bahan kimia diubah menjadi bentuk lain. Laju reaksi ditunjukkan oleh massa produk yang dihasilkan tiap satuan waktu. Pada umumnya, laju reaksi dapat ditunjukkan dengan mengamati konsentrasi reaktan dan hasil reaksi (Yanuari, 2017). Kinetika reaksi dasar dihitung dari masing-masing produk yang disimpan pada suhu chilling $5^{\circ} \mathrm{C}$ dan suhu ruang $30^{\circ} \mathrm{C}$ yang diuji setiap hari sampai hari ke 7 melalui analisa mutu nilai kadar air dan sensori.

\section{Pengujian kadar air}

Kadar air merupakan salah satu penentu pada pengujian umur simpan otak-otak ikan dikarenakan kadar air berpengaruh dalam menentukan daya awet dari bahan pangan, di antaranya sifat-sifat fisik, kandungan kimia, serta kebusukan karena mikroorganisme. Kadar air dalam suatu bahan pangan perlu ditetapkan, karena semakin tinggi kadar air yang terdapat dalam suatu bahan pangan maka semakin besar pula kemungkinan bahan pangan tersebut rusak atau tidak tahan lama (Fitriani, 2020). Hasil Pengujian Kadar Air pada Otak-otak Ikan 
Buletin JSJ, 2 (2), 2020, 101-112

Available online di: http://ejournal-balitbang.kkp.go.id/index.php/JSJ/index

UMKM Bunga Mawar dapat di lihat pada Tabel 3.

Tabel 3. Hasil Pegujian Kadar Air pada Otak-Otak Ikan UMKM Bunga Mawar

\begin{tabular}{ccccccccc}
\hline $\begin{array}{l}\text { Suhu } \\
\left({ }^{\circ} \mathrm{C}\right)\end{array}$ & 0 & 1 & 2 & 3 & 4 & 5 & 6 & 7 \\
\hline $5^{\circ} \mathrm{C}$ & 50,19 & 53,3 & 55,5 & 58,22 & 61,03 & 63,8 & 65,23 & 66,9 \\
$30^{\circ} \mathrm{C}$ & 50,19 & 54,32 & 59,45 & 62,48 & 65,82 & 68,31 & 70,75 & 72,83 \\
\hline
\end{tabular}

Berdasarkan data dari Tabel 3 otak-otak ikan yang dikemas dengan plastik polietilen mengalami kenaikan kadar air selama penyimpanan Pada suhu $5^{\circ} \mathrm{C}$ mengalami peningkatan $16,71 \%$ dan pada suhu $30^{\circ} \mathrm{C}$ mengalami peningkatan $22,64 \%$, karena kadar air dalam permukaan bahan dipengaruhi oleh kelembaban nisbi $(\mathrm{RH})$ udara di sekitarnya. Apabila kadar air rendah sedangkan $\mathrm{RH}$ di sekitarnya tinggi, maka akan terjadi penyerapan uap air dari udara sehingga bahan menjadi lembab atau kadar airnya menjadi lebih tinggi (Falahuddin, 2009). Peningkatan kadar air yg cukup tinggi ini dipengaruhi oleh kelembaban suhu ruang. Semakin tinggi nilai kelembaban udara, maka semakin banyak kandungan uap airnya sehingga kadar air produk meningkat (Sakti et al., 2016). Menurut Susilo (2012) dan Lobo et al., (2013), peningkatan kadar air juga disebabkan oleh bahan kemasan selama penyimpanan yang dipengaruhi oleh permeabilitas bahan kemasan polietilen terhadap uap air lebih tinggi, sifat higroskopis bahan pangan yang dikemas dan tingkat kelembapan udara lingkungan terhadap produk pangan.

Dari hari pengujian air tersebut kemudian didapatkan persamaan regresi ordo 0 dan ordo 1 $\mathrm{y}=\mathrm{a}+\mathrm{bx}$ pada parameter kadar air di masing-masing suhu penyimpanan. Laju Perubahan Mutu Kadar Air Ordo 0 (nol) dan Ordo 1 (satu) dapat dilihat pada Gambar 5 dan Gambar 6. Regresi Linier Parameter Kadar Air dapat dilihat pada Tabel 4.
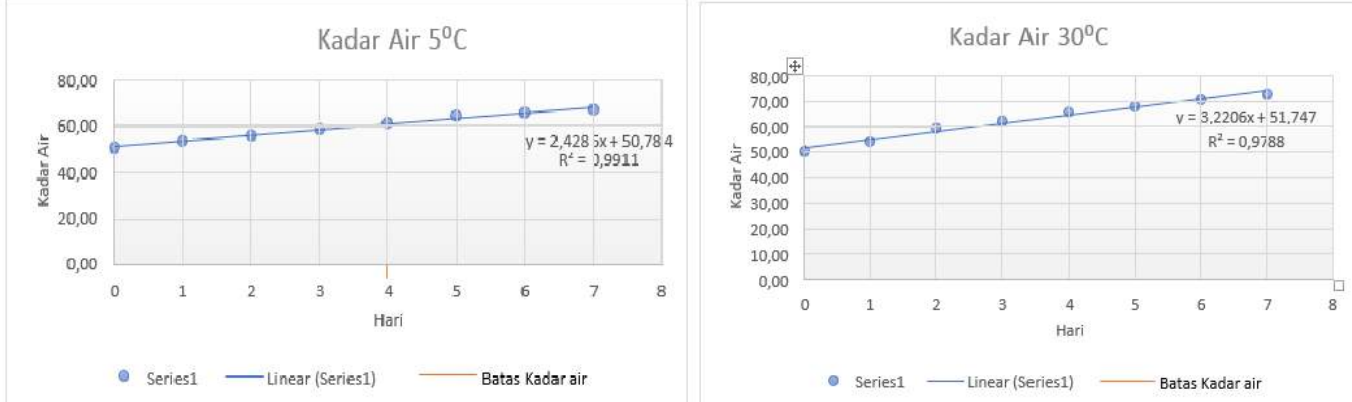

Gambar 5. Laju Perubahan Mutu Kadar Air Ordo 0 (Nol)
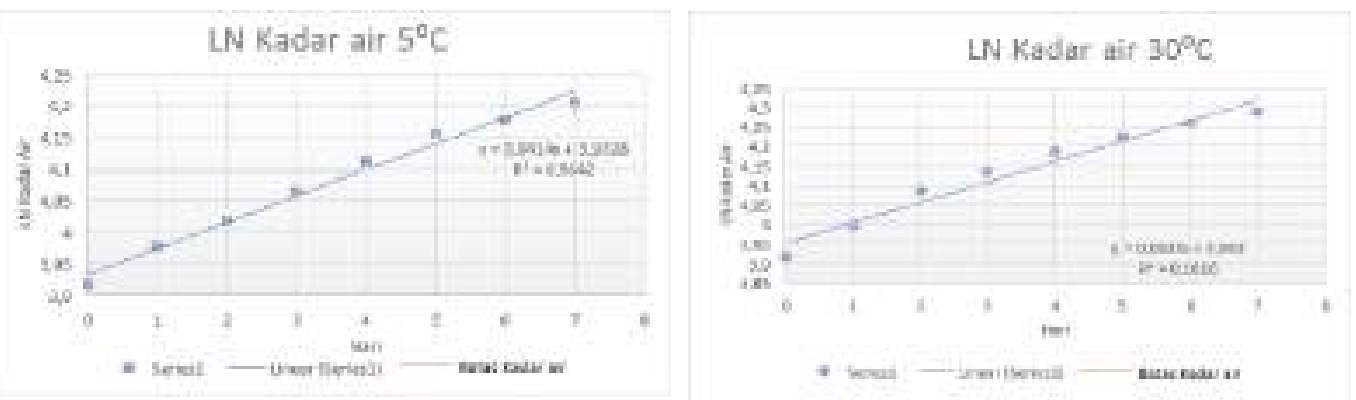

Gambar 6. Laju Perubahan Mutu Ln Kadar Air Ordo 1 (Satu) 
Buletin JSJ, 2 (2), 2020, 101-112

Available online di: http://ejournal-balitbang.kkp.go.id/index.php/JSJ/index

Tabel 4. Regresi Linier Parameter Kadar Air

\begin{tabular}{ccccc}
\hline Suhu $\left({ }^{\circ} \mathbf{C}\right)$ & \multicolumn{2}{c}{ Regresi linear } & $\mathbf{R}^{\mathbf{2}}$ \\
\cline { 2 - 5 } & Orde 0 & Orde 1 & Orde 0 & Orde 1 \\
\hline $\mathbf{5}$ & $\mathrm{y}=2,4286 \mathrm{x}+50,784$ & $\mathrm{y}=0,0414 \mathrm{x}+3,9328$ & 0,9911 & 0,9842 \\
$\mathbf{3 0}$ & $\mathrm{y}=3,2206 \mathrm{x}+51,747$ & $\mathrm{y}=0,0523 \mathrm{x}+3,953$ & 0,9788 & 0,9616 \\
\hline
\end{tabular}

Berdasarkan Tabel 4 dapat diketahui bahwa koefisien determinasi $\left(\mathrm{R}^{2}\right)$ ordo 0 lebih besar dari koefisien determinasi ordo 1. Dengan demikian ordo 0 merupakan ordo reaksi yang digunakan untuk penentuan umur simpan dengan korelasi penurunan kualitas mutu terhadap suhu penyimpanan.

Prediksi umur simpan dengan Extended Storage Studies (ESS) menggunakan asumsi bahwa produk sudah mengalami penurunan kualitas yang signifikan ketika kadar air pada produk sudah mencapai $60 \%$, karena menurut SNI 7757:2013 otak-otak ikan yang baik memiliki kadar air maksimal $60 \%$. Sehingga dari nilai laju kemunduran ini kita bisa memprediksi nilai umur simpan otak otak yang disimpan pada suhu $5^{\circ} \mathrm{C}$ adalah 3 hari dan pada suhu $30^{\circ} \mathrm{C}$ adalah 2 hari.

\section{Pengujian sensori}

Pengujian sensori menggunakan kuesioner. Hasil perhitungan sensori otak- otak ikan pada parameter sensori dapat dilihat pada Tabel 5.

Tabel 5. Hasil Pengujian Sensori pada Otak-Otak Ikan UMKM Bunga Mawar

\begin{tabular}{ccccccccc}
\hline $\begin{array}{l}\text { Suhu } \\
\left({ }^{\circ} \mathrm{C}\right)\end{array}$ & 0 & 1 & 2 & 3 & 4 & 5 & 6 & 7 \\
\hline $5^{\circ} \mathrm{C}$ & 8,94 & 8,44 & 7,47 & 7,06 & 6,42 & 5,44 & 4,92 & 4,42 \\
$30^{\circ} \mathrm{C}$ & 8,94 & 7,83 & 6,25 & 5,08 & 4,33 & 4,08 & 3,67 & 3,56 \\
\hline
\end{tabular}

Pada Tabel 5. menunjukkan bahwa semakin lama penyimpanan otak-otak ikan semakin rendah penilaian panelis dalam menerima produk tersebut. Artinya terjadi penurunan mutu pada otak-otak ikan sehingga mempengaruhi penilaian panelis terhadap parameter sensori yaitu kenampakan, bau, rasa dan tekstur dari otak- otak ikan. Pada suhu penyimpanan $5^{\circ} \mathrm{C}$ mengalami penurunan dari nilai 8,94 ke 4,42 pada hari ke-0 hingga hari ke-7 dan pada suhu penyimpanan $30^{\circ} \mathrm{C}$ mengalami penurunan dari 8,94 ke 3,56 pada hari ke 7 . Dari kedua suhu penyimpanan tersebut penilaian sensori terhadap otak-otak ikan terus menurun dengan nilai sensori terendah didapatkan pada suhu penyimpanan $30^{\circ} \mathrm{C}$. Penurunan nilai sensori otak-otak ikan apabila diplotkan antara lamanya hari dengan nilai sensori akan menghasilkan grafik ordo 0 , dan lamanya waktu diplotkan kembali dengan Ln dari nilai sensori maka menghasilkan grafik ordo 1. Laju perubahan nilai sensori berdasarkan ordo 0 dan ordo 1 dapat dilihat pada Gambar 8 dan Gambar 7. Regresi Linear Parameter sensori dapat dilihat pada Tabel 6.
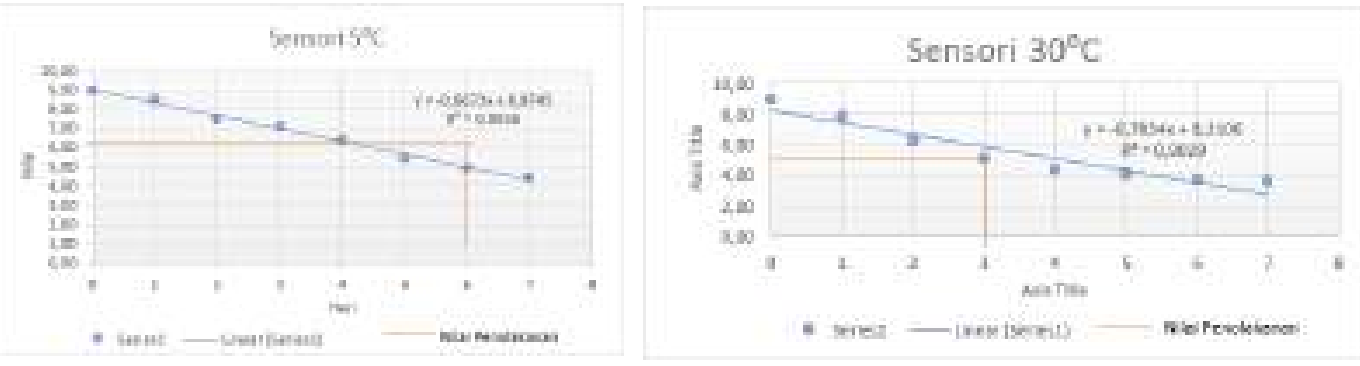

Gambar 7. Laju Perubahan Mutu Sensori Ordo 0 (Nol) 
Buletin JSJ, 2 (2), 2020, 101-112

Available online di: http://ejournal-balitbang.kkp.go.id/index.php/JSJ/index
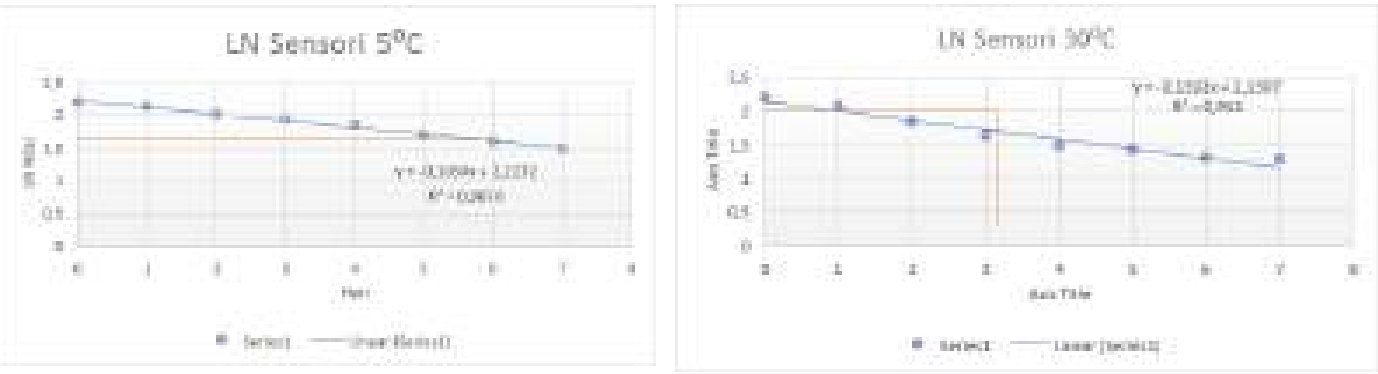

Gambar 8. Laju Perubahan Ln Mutu Sensori Ordo 1 (Satu)

Tabel 6. Regresi Linear Parameter Sensori

\begin{tabular}{ccccc}
\hline Suhu $\left({ }^{\circ} \mathbf{C}\right)$ & \multicolumn{2}{c}{ REGRESI LINEAR } & \multicolumn{2}{c}{ NILAI R $^{2}$} \\
& Ordo 0 & Ordo 1 & Ordo 0 & Ordo 1 \\
\hline 5 & $y=-0,6835 x+9,0069$ & $y=-0,1009 x+2,2221$ & 0,9925 & 0,9823 \\
30 & $y=-0,7834 x+8,2106$ & $y=-0,1392 x+2,1307$ & 0,9029 & 0,952 \\
\hline
\end{tabular}

Plot data pengamatan perubahan nilai sensori otak-otak menghasilkan persamaan regresi linier $y=a x+b$ di mana $y=$ nilai perubahan nilai sensori, $a=$ laju perubahan nilai Organoleptik, $x=$ lama penyimpanan, $b=$ nilai perubahan nilai sensori pada awal penyimpanan. Dari hasil analisa regresi linier otak-otak ikan diperoleh koefisien determinan $\left(R^{2}\right)$ yang mendekati 1 , berarti faktor suhu dan atau lama penyimpanan mempengaruhi tingkat penerimaan panelis terhadap otak-otak ikan.

Berdasarkan hasil persamaan regresi pada Tabel 6 kemudian dipilih ordo reaksi yang digunakan dengan cara memilih koefisien determinan $\left(R^{2}\right)$ tertinggi yaitu ordo 0 , karena nilai $R^{2}$ pada suhu $5^{\circ} \mathrm{C}$ nilai $R^{2}$ lebih besar dari $R^{2}$ pada ordo 1 walaupun pada suhu penyimpanan $30^{\circ} \mathrm{C}$ nilai $R^{2}$ pada ordo 1 lebih besar dari ordo 0 tetap menggunakan ordo 0 karena nilai $R^{2}$ tidak terlalu jauh. Sehingga penurunan nilai sensori mengikuti reaksi ordo 0 yang artinya penerimaan keseluruhan otak-otak ikan terus menurun semakin lama produk tersebut disimpan. Nilai penolakan sensori pada tiap suhu penyimpanan adalah 5 , karena nilai 5 pada tiap parameter sensori (kenampakan, bau, rasa, tekstur) menjelaskan bahwa mutu produk otak-otak ikan sudah tidak baik dan tidak aman jika dikonsumsi.

Umur simpan otak-otak ikan UMKM Bunga Mawar berasarkan parameter sensori yang disimpan pada suhu $5^{\circ} \mathrm{C}$ adalah 6 hari dan pada suhu $30^{\circ} \mathrm{C}$ adalah 3 hari yang didapatkan berdasarkan parameter sensori dengan nilai penolakan pada tiap suhu penyimpanan adalah 5 .

\section{Penentuan Umur Simpan}

Berdasarkan hasil dari kinetika reaksi dasar dengan pengujian kadar air, sensori maka didapatkan umur simpan. Umur simpan otak-otak ikan UMKM Bunga mawar yang dibungkus menggunakan platik PE tanpa divakum pada suhu $5^{\circ} \mathrm{C}$ adalah 6 hari dan pada suhu $30^{\circ} \mathrm{C}$ adalah 3 hari yang didapatkan berdasarkan parameter sensori dengan nilai penolakan pada tiap suhu penyimpanan adalah 5 . 
Buletin JSJ, 2 (2), 2020, 101-112

Available online di: http://ejournal-balitbang.kkp.go.id/index.php/JSJ/index

\section{KESIMPULAN DAN SARAN}

\section{Kesimpulan}

Mutu otak-otak ikan UMKM Bunga Mawar sesuai dengan SNI (7757:2013). Nilai sensori produk otak-otak ikan adalah 9 Kadar air 50,19\%. Umur simpan otak-otak ikan UMKM Bunga Mawar yang dibungkus menggunakan plastik PE tanpa divakum pada suhu $5^{\circ} \mathrm{C}$ adalah 6 hari dan pada suhu $30^{\circ} \mathrm{C}$ adalah 3 hari.

\section{Saran}

Perlu dilakukan perubahan label kemasan dengan mencantumkan umur simpan otak-otak UMKM Bunga Mawar sesuai dengan label kemasan.

\section{DAFTAR PUSTAKA}

Alifah, F. N. (2016). Pendugaan Umur Simpan Otak-Otak Ikan Tenggiri (Scomberomorus Commersonii) yang Dikemas Edible Coating Antimikroba Menggunakan Metode Accelerated Shelf Life Testing (Aslt) Model Arrhenius [Tugas Akhir]. Universitas Pasundan.

Ariska, R. (2020). Kajian Pembuatan Otak-Otak Ikan Patin Dengan Penambahan Bayam Merah (Amaranthus Tricolor L.) Terhadap Sifat Organoleptik, Kadar Zat Besi Dan Seratuntuk Remaja Putri [Tugas Akhir]. Politeknik Kesehatan Tanjung Karang.

Budiarti, I. D. S., Swastawati, F., \& Rianingsih, L. (2016). Pengaruh Perbedaan Lama Perendaman Dalam Asap Cair Terhadap Perubahan Komposisi Asam Lemak Dan Kolesterol Belut (Monopterus albus) ASAP. J. Peng. \& Biotek. Hasil Pi., 5 No. 1 Th. 2016.

Falahuddin, N. (2009). Kitosan sebagai edible coating pada otak-otak bandeng yang dikemas vakum. Institut Pertanian Bogor.

Fitriani, W. M. (2020). Pendugaan Umur Simpan Dengan Metode Accelerated Shelf Life Test Dengan Pendekatan Arrhenius Pada Produk Nugget Ikan Gabus (Channa striata) [Tugas Akhir]. Universitas Pasundan.

Lobo, Y., Diah, K., \& Arda, G. (2013). Studi Pengaruh Jenis Kemasan Dan Ketebalan Plastik Terhadap Karakteristik Mutu Rebung Bambu Tabah (Gigantochloa nigrociliata kurz) Kering. Teknik Pertanian Fakultas Teknologi Pertanian Universitas Udayana.

Padli. (2015). Profil Penurunan Mutu Otak-Otak Ikan Tenggiri (Scomberomorus commersonii) pada Berbagai Suhu Penyimpanan [Skripsi]. Fakultas Pertanian Universitas Hasanuddin.

Putra, D. A. P., Tri, W. A., \& Wijayanti, I. (2015). Pengaruh Penambahan Karagenan Sebagai Stabilizer Terhadap Karakteristik Otak-Otak Ikan Kurisi (Nemipterus nematophorus). Jurnal Pengolahan dan Bioteknologi Hasil Perikanan, Volume 4, Nomer 2,Tahun 2015, Halaman 1-10.

Rahmadya, B., Derisma, Yolanda, D., \& Yendri, D. (2018). Alat Penghitung Jumlah Kalori dan Pengatur Pola Makan Pasien di Puskesmas Kebun Sikolos Kelurahan Kampung Manggis Padang Panjang [Laporan akhir]. Universitas Andalas.

Rahussidi, M. A., Sumardianto, \& Wijayanti, I. (2016). Pengaruh Perbandingan Konsentrasi Tepung Tapioka (Manihot uttilissima) Dan Tepung Kentang (Solanum tuberosum) Terhadap Kualitas Bakso Ikan Lele (Clarias batrachus). J. Peng. \& Biotek. Hasil Pi, Vol. 5 No. 3 Th. 2016.

Rohmah, R. A. (2017). Bagaimana menuliskan Informasi Nilai Gizi pada label pangan olahan, Informasi Obat dan Makanan. https://bpom- yogya.blogspot.com/2017/08/bagaimanamenuliskan-informasi-nilai.html

Sakti, H., Lestari, S., \& Supriadi, A. (2016). Perubahan Mutu Ikan Gabus (Channa striata) Asap selama Penyimpanan. FishtecH \pm Jurnal Teknologi Hasil Perikanan.

Susilo, A. H. (2012). Pendugaan umur simpan bahan makanan campuran (BMC) dari tepung 
Buletin JSJ, 2 (2), 2020, 101-112

Available online di: http://ejournal-balitbang.kkp.go.id/index.php/JSJ/index

sukun (Artocarpus communis) dan tepung kacang benguk germinasi (Mucuna pruriens L.) Pada kemasan plastik poliethilen dengan metode akselerasi [Skripsi]. Fakultas pertanian. Universitas lampung.

Syarief, R., Santausa, S., \& Isyana, S. T. (1989). Teknologi pengemasan pangan. Laboratorium Rekayasa Proses Pangan, PAU Pangan dan Gizi, IPB.

Winarno, F.G. (2011). GMP Good Manufacturing Practices ( Cara Pengolahan Pangan Yang Baik). Bogor: M-BRIO PRESS.

Yanuari. (2017). Pendugaan Umur Simpan Abon Lele Menggunakan Metode Accelerated Shelf Life Testing (ASLT) dengan Pendekatan Arrhenius [Skripsi]. Universitas Brawijaya. 